\title{
Square Sum Labeling for Some Middle and Total Graphs
}

\author{
J.Shiama \\ Asst. Professor \\ Dept. of Mathematics \\ Cms College of Science and Commerce, \\ Coimbatore- 641049, Tamilnadu, India
}

\begin{abstract}
A (p, q) graph $G$ is said to be a square sum graph if there exist a bijection $\mathrm{f:} V(\mathrm{G}) \rightarrow\{0,1,2, \ldots \mathrm{p}-1\}$ such that the induced function $\mathrm{f}^{*}: \mathrm{E}(\mathrm{G}) \rightarrow \mathrm{N}$ given by $\mathrm{f}^{*}(\mathrm{u} v)=\left[\mathrm{f}^{*}(\mathrm{u})\right]^{2}+\left[\mathrm{f}^{*}(\mathrm{v})\right]^{2}$ for every $u v \in E(G)$ are all distinct. In this paper the square sum labeling of total graph of path $P_{n}$, cycle $C_{n}$ and middle graph of path $P_{n}$, cycle $C_{n}$ are discussed.
\end{abstract}

\section{GeneraTerms}

Middle graph, Total graph of cycle $\mathrm{C}_{\mathrm{n}}$ and path $\mathrm{P}_{\mathrm{n}}$ are denoted by $\mathrm{M}\left(\mathrm{P}_{, \mathrm{n}}\right), \mathrm{M}\left(\mathrm{C}_{, \mathrm{n}}\right)$ and $\mathrm{T}\left(\mathrm{P}_{\mathrm{n}}\right), \mathrm{T}\left(\mathrm{C}_{\mathrm{n}}\right)$ respectively.

\section{Keywords}

Middle graph, Total graph, square sum labeling

\section{INTRODUCION}

If the vertices of the graph are assigned values subject to certain conditions is known as graph labeling. A dynamic survey on graph labeling is regularly updated by Gallian [3] and it is published by Electronic Journal of Combinatory. Vast amount of literature is available on different types of graph labeling and more than 1000 research papers have been published so far in past three decades.

For any labeling problems following three characteristics are really note-worthy

\footnotetext{
* A set of numbers from which vertex labels are chosen;

* A rule that assigns a value to each edge;
}

* A condition that these values must satisfy. The present work is aimed to discuss one such a labeling namely square sum labeling.

Beginning with simple, finite, connected and undirected graph $\mathrm{G}=(\mathrm{V}(\mathrm{G}), \mathrm{E}(\mathrm{G}))$ with $\mathrm{p}$ vertices and $\mathrm{q}$ edges. For all other terminology and notations in graph theory I follow West [5].Some brief summary of definitions which are useful for the present investigations.

\section{Definition1.1}

Let $\mathrm{G}=(\mathrm{V}(\mathrm{G}), \mathrm{E}(\mathrm{G}))$ be a graph is said to be a square sum graph [4] if there exist a bijection $\mathrm{f:} V(\mathrm{G}) \rightarrow\{0,1,2, \ldots . \mathrm{p}-1\}$ such that the induced function $\mathrm{f}^{*}: \mathrm{E}(\mathrm{G}) \rightarrow \mathrm{N}$ given by $\mathrm{f}^{*}(\mathrm{u} \mathrm{v})=\left[\mathrm{f}^{*}(\mathrm{u})\right]^{2}+\left[\mathrm{f}^{*}(\mathrm{v})\right]^{2}$ for every $\mathrm{uv} \in \mathrm{E}(\mathrm{G})$ are all distinct.

\section{Definition1.2}

The middle graph [1] of $G$ denoted by $M(G)$ is $\mathrm{V}(\mathrm{G}) \mathrm{UE}(\mathrm{G})$.Two vertices $\mathrm{x}$, $\mathrm{y}$ in the vertex set of $\mathrm{M}(\mathrm{G})$ are adjacent in $\mathrm{M}(\mathrm{G})$ in case one of the following holds (i) $x, y$ are in $E(G)$ and $x, y$ are adjacent in $G$. (ii) $x$ is in $V(G)$ , $y$ is in $E(G), x$ and $y$ are incident in $G$

\section{Definition1.3}

The total graph [1] of G, denoted by $\mathrm{T}(\mathrm{G})$ in case one of the following holds (i) $x, y$ are in $V(G)$ and $x$ is adjacent to $y$ in $G$ (ii) $\mathrm{x}, \mathrm{y}$ are in $\mathrm{E}(\mathrm{G})$ and $\mathrm{x}, \mathrm{y}$ are adjacent in $\mathrm{E}(\mathrm{G})$ (iii) $\mathrm{x}$ is in $V(G), y$ is in $E(G)$ and $x, y$ are incident in $G$.

\section{MAINRESULTS}

\section{Theorem-2.1}

The Middle graph $\mathrm{M}\left(\mathrm{P}_{\mathrm{n}}\right)$ of a path $\mathrm{P}_{\mathrm{n}}$ admits square sum labeling.

\section{Proof}

Let $P_{n}$ be a path of length $n-1$ with vertices $u_{1}, u_{2}, \ldots u_{n}$. Let $v_{j}$ $=u_{j} u_{j+1}$ for $1 \leq j \leq n-1$ be the edges of path $P_{n}$

Let $G$ be the middle graph of path $P_{n}$. Here $V(G)=V\left(M\left(P_{n}\right)\right)=$ $\left\{\mathrm{u}_{\mathrm{i},} \mathrm{v}_{\mathrm{j}} / 1 \leq \mathrm{i} \leq \mathrm{n}, 1 \leq \mathrm{j} \leq \mathrm{n}-1\right\}$ and $\mathrm{E}(\mathrm{G})=\left\{\mathrm{v}_{\mathrm{j}} \mathrm{v}_{\mathrm{j}+1}, \mathrm{u}_{\mathrm{i}} \mathrm{v}_{\mathrm{i}}, \mathrm{v}_{\mathrm{i}} \mathrm{u}_{\mathrm{i}+1} / 1 \leq\right.$ $\mathrm{i} \leq \mathrm{n}-1,1 \leq \mathrm{j} \leq \mathrm{n}-2\}$. Here $|\mathrm{V}(\mathrm{G})|=2 \mathrm{n}-1$ and $|\mathrm{E}(\mathrm{G})|=3 \mathrm{n}-4$ Define $\mathrm{f:} \mathrm{V}(\mathrm{G}) \rightarrow\{0,1,2, \ldots . \mathrm{q}-1\}$ as $\mathrm{f}\left(\mathrm{u}_{\mathrm{i}}\right)=\mathrm{i}-1$ if $1 \leq \mathrm{i} \leq \mathrm{n}-1$ and

$f\left(v_{j}\right)=j+2$ if $1 \leq j \leq n-2$

And $\mathrm{f}$ induces a function $\mathrm{f}^{*}$ by $\mathrm{f}^{*}\left(\mathrm{u}_{\mathrm{i}} \mathrm{v}_{\mathrm{i}}\right)=\left[\mathrm{f}^{*}\left(\mathrm{u}_{\mathrm{i}}\right)\right]^{2}+\left[\mathrm{f}^{*}\left(\mathrm{v}_{\mathrm{i}}\right)\right]^{2}$ Thus for any edge $f^{*}\left(e_{i}\right) \neq f^{*}\left(e_{j}\right), i \neq j$

\section{Example-2.2}

The middle graph of a path $\mathrm{P}_{4}$ i.e $\mathrm{M}\left(\mathrm{P}_{4}\right)$ is shown in figure -1 


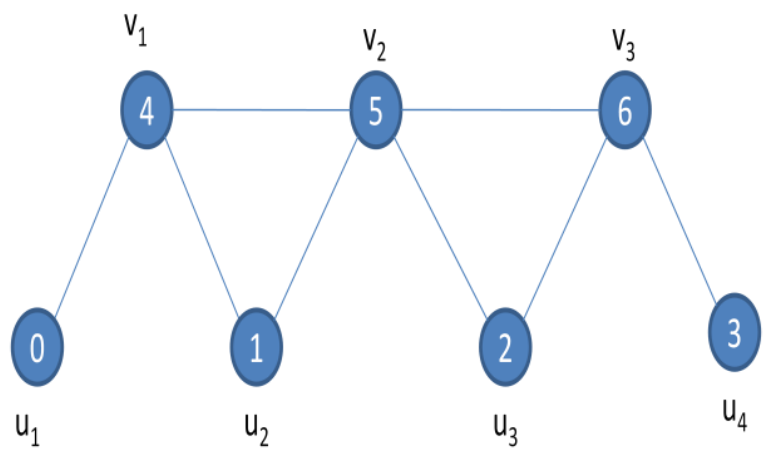

Figure-1

\section{Theorem-2.3}

The Middle graph $M\left(C_{n}\right)$ of a cycle $C_{n}$ is a square sum graph.

\section{Proof}

Let $\mathrm{C}_{\mathrm{n}}$ be the cycle with vertices $\mathrm{u}, \mathrm{u}_{2}, \ldots \mathrm{u}_{\mathrm{n}}$. Let $\mathrm{v}_{\mathrm{i}}=\mathrm{u}_{\mathrm{i}} \mathrm{u}_{\mathrm{i}+1}$ for $1 \leq \mathrm{i} \leq \mathrm{n}-1$ be the edges of cycle $\mathrm{C}_{\mathrm{n}}$. Let $\mathrm{G}$ be the middle graph of cycle $\mathrm{C}_{\mathrm{n}}$. Here $\mathrm{V}(\mathrm{G})=\mathrm{V}\left(\mathrm{M}\left(\mathrm{C}_{\mathrm{n}}\right)\right)=\left\{\mathrm{u}_{\mathrm{i}} \mathrm{v}_{\mathrm{i}} / 1 \leq \mathrm{i} \leq \mathrm{n}\right\}$ and $\mathrm{E}(\mathrm{G})=\mathrm{E}\left(\mathrm{M}\left(\mathrm{C}_{\mathrm{n}}\right)\right)=\left\{\mathrm{v}_{\mathrm{i}} \mathrm{v}_{\mathrm{i}+1}, \mathrm{u}_{\mathrm{i}} \mathrm{v}_{\mathrm{i}}, \mathrm{v}_{\mathrm{i}} \mathrm{u}_{\mathrm{i}+1} / 1 \leq \mathrm{i} \leq \mathrm{n}-1,1 \leq \mathrm{j} \leq \mathrm{n}-\right.$ 2\} Here $|\mathrm{V}(\mathrm{G})|=2 \mathrm{n}$ and $|\mathrm{E}(\mathrm{G})|=3 \mathrm{n}$ Define $\mathrm{f}$ : $\mathrm{V}(\mathrm{G}) \rightarrow\{0,1,2, \ldots .2 \mathrm{n}-1\}$ as $\mathrm{f}\left(\mathrm{u}_{\mathrm{i}}\right)=\mathrm{i}-1$ if $1 \leq \mathrm{i} \leq \mathrm{n} \quad \mathrm{f}\left(\mathrm{v}_{\mathrm{j}}\right)=2 \mathrm{j}+1$ if $1 \leq \mathrm{j} \leq \mathrm{n}-1$ and $\mathrm{f}\left(\mathrm{v}_{\mathrm{j}}\right)=2 \mathrm{j}-2$ if $\mathrm{j}=\mathrm{n}$ And $\mathrm{f}$ induces a function $\mathrm{f}^{*}$ by $f^{*}\left(u_{i} v_{i}\right)=\left[f^{*}\left(u_{i}\right)\right]^{2}+\left[f^{*}\left(v_{i}\right)\right]^{2} \quad$ Thus for any edge $f^{*}\left(e_{i}\right) \neq$ $f^{*}\left(e_{j}\right), i \neq j$

\section{Example-2.4}

The middle graph of cycle $C_{3}$ i.e $M\left(C_{3}\right)$ is shown in figure-2

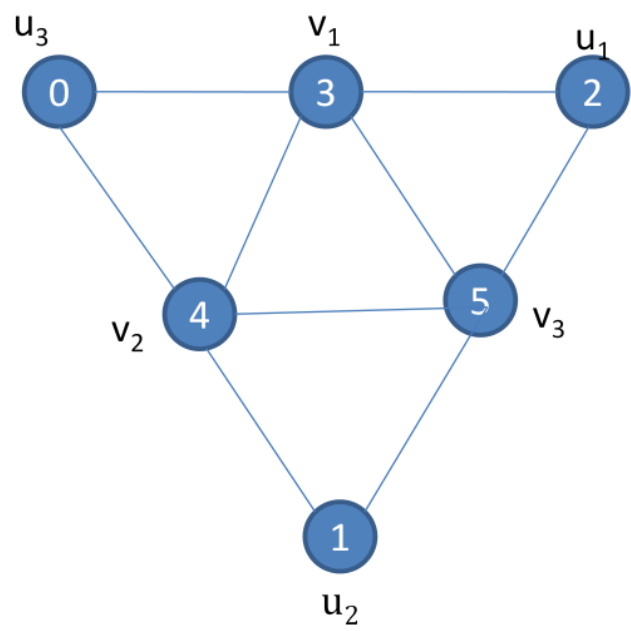

Figure-2

\section{Theorem-2.5}

The Total graph $\mathrm{T}\left(\mathrm{P}_{\mathrm{n}}\right)$ of a path $\mathrm{P}_{\mathrm{n}}$ with $\mathrm{n}-1$ edges admits squaresumlabeling.

\section{Proof}

Let $P_{n}$ be a path of length $n-1$ with vertices $u_{1}, u_{2}, \ldots u_{n}$. Let $v_{j}=u_{j} u_{j+1}$ for $1 \leq j \leq n-1$ be the edges of path $P_{n} \quad f\left(u_{i}\right)=2 i-2$ if $1 \leq \mathrm{i} \leq \mathrm{n} \quad$ The labeling is defined as follows $\mathrm{f}: \mathrm{V}(\mathrm{G})$ $\rightarrow\{0,1,2, \ldots, 2 \mathrm{n}-1\}$ by $\mathrm{f}\left(\mathrm{v}_{\mathrm{j}}\right)=2 \mathrm{j}-1$ if $1 \leq \mathrm{j} \leq \mathrm{n}-2$ Let $\mathrm{G}$ be the
Total graph of path $P_{n}$. Here $V(G)=V\left(T\left(P_{n}\right)\right)=\left\{u_{i}, v_{j} / 1 \leq i\right.$ $\leq \mathrm{n}, 1 \leq \mathrm{j} \leq \mathrm{n}-1\}$ and $\mathrm{E}(\mathrm{G})=\left\{\mathrm{v}_{\mathrm{j}} \mathrm{v}_{\mathrm{j}+1}, \mathrm{u}_{\mathrm{i}} \mathrm{v}_{\mathrm{i}}, \mathrm{v}_{\mathrm{j}} \mathrm{u}_{\mathrm{i}+1}, \mathrm{u}_{\mathrm{i}} \mathrm{u}_{\mathrm{i}+1}, / 1 \leq \mathrm{i}\right.$ $\leq \mathrm{n}-1,1 \leq \mathrm{j} \leq \mathrm{n}-1\}$. Here $|\mathrm{V}(\mathrm{G})|=2 \mathrm{n}-1$ and $|\mathrm{E}(\mathrm{G})|=3 \mathrm{n}$ And $\mathrm{f}$ induces a function $\mathrm{f}^{*}$ by $\mathrm{f}^{*}\left(\mathrm{u}_{\mathrm{i}} \mathrm{v}_{\mathrm{i}}\right)=\left[\mathrm{f}^{*}\left(\mathrm{u}_{\mathrm{i}}\right)\right]^{2}+\left[\mathrm{f}^{*}\left(\mathrm{v}_{\mathrm{i}}\right)\right]^{2}$ Thus for any edge $f^{*}\left(e_{i}\right) \neq f^{*}\left(e_{j}\right), i \neq j$

\section{Example-2.6}

The total graph $\mathrm{T}\left(\mathrm{P}_{5}\right)$ is shown in figure-3

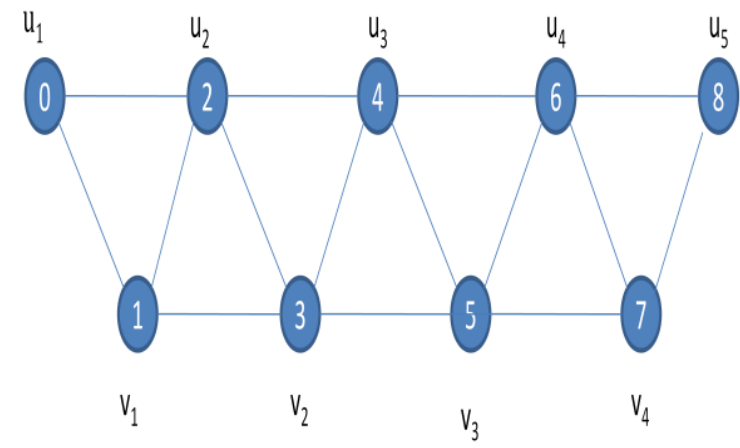

Figure-3

\section{Theorem-2.7}

The total graph $T\left(C_{n}\right)$ of a cycle $C_{n}$ admits square sum labeling.

Proof

Let $\mathrm{C}_{\mathrm{n}}$ be the cycle with vertices $\mathrm{u}_{1}, \mathrm{u}_{2}, \ldots \mathrm{u}_{\mathrm{n}}$. Let $\mathrm{v}_{\mathrm{i}}=\mathrm{u}_{\mathrm{i}} \mathrm{u}_{\mathrm{i}+1}$ for $1 \leq \mathrm{i} \leq \mathrm{n}-1$ be the edges of cycle $\mathrm{C}_{\mathrm{n}}$. Let $\mathrm{G}$ be the total graph of cycle $C_{n}$. Here $V(G)=V\left(M\left(C_{n}\right)\right)=\left\{u_{i} v_{i} / 1 \leq i \leq n\right\}$ and $\mathrm{E}(\mathrm{G})=\mathrm{E}\left(\mathrm{M}\left(\mathrm{C}_{\mathrm{n}}\right)\right)=\left\{\mathrm{u}_{\mathrm{i}} \mathrm{u}_{\mathrm{i}+1}, \mathrm{v}_{\mathrm{j}} \mathrm{v}_{\mathrm{j}+1}, \mathrm{u}_{\mathrm{i}} \mathrm{v}_{\mathrm{i}}, \mathrm{v}_{\mathrm{j}} \mathrm{u}_{\mathrm{i}+1} / 1 \leq \mathrm{i} \leq \mathrm{n}-1,1 \leq \mathrm{j}\right.$ $\leq \mathrm{n}-2\}$ and $|\mathrm{V}(\mathrm{G})|=2 \mathrm{n}$ and $|\mathrm{E}(\mathrm{G})|=4 \mathrm{n}$. Define $\mathrm{f}$ : $\mathrm{V}(\mathrm{G}) \rightarrow\{0,1,2, \ldots 2 \mathrm{n}-1\}$ as $\mathrm{f}\left(\mathrm{u}_{\mathrm{i}}\right)=\mathrm{i}-1$ if $1 \leq \mathrm{i} \leq \mathrm{n} \quad \mathrm{f}\left(\mathrm{v}_{\mathrm{j}}\right)=\mathrm{j}+3$ if $1 \leq \mathrm{j} \leq \mathrm{n}$ And $\mathrm{f}$ induces a function $\mathrm{f}^{*}$ by $\mathrm{f}^{*}\left(\mathrm{u}_{\mathrm{i}} \mathrm{v}_{\mathrm{i}}\right)=\left[\mathrm{f}^{*}\left(\mathrm{u}_{\mathrm{i}}\right)\right]^{2}$ $+\left[f^{*}\left(v_{i}\right)\right]^{2}$ for any edge $f^{*}\left(e_{i}\right) \neq f^{*}\left(e_{j}\right), i \neq j$

\section{Example-2.8}

The total graph of a cycle $\mathrm{C}_{4}$ i.e $\mathrm{T}\left(\mathrm{C}_{4}\right)$ is shown in figure- 4

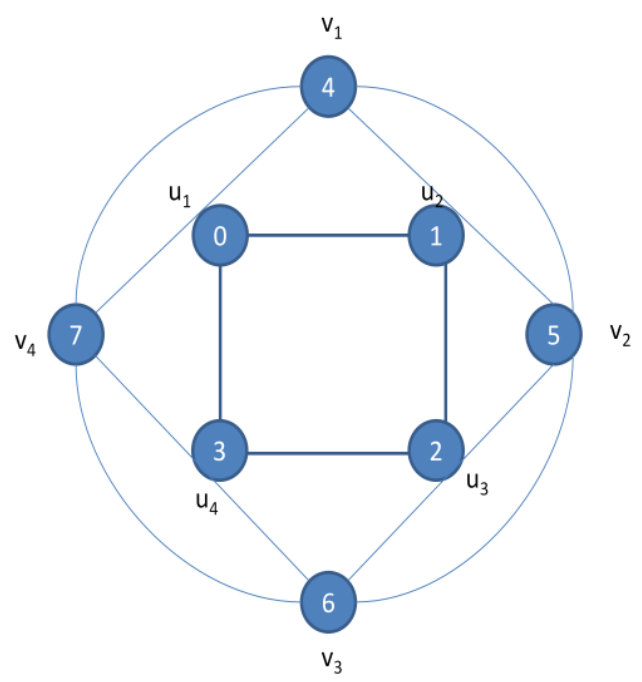

Figure-4 


\section{CONCLUSION}

As every graph is not a square sum graphs, it is very interesting as well as challenging to investigate graph or graph families which admits square sum labeling. Here four results on square sum labeling are investigated .This can be extended to some other graphs.

\section{ACKNOWLEDGEMENTS}

The author is thankful to the referee for the valuable comments which led to the substantial improvement in the paper.

\section{REFERENCES}

[1] Danuta Michalak, On middle and total graphs with coarseness number equal 1, Spinger Verlag Graph Theory, Lagow (1981) proceedings, Berlin heidelberg, New York, Tokyo, pp. 139-150.

[2] Frank Harrary, Graph theory, Narosa Publishing House(2001).

[3] J A Gallian, A dynamic survey of graph labeling, The Electronics journal of Combinatories,17(2010) \# DS6

[4] Square sum labeling by K.A.Germina

[5] D B West, Introduction to Graph Theory, Prentice-Hall, India,2001 